\title{
Libros, lectores y lectura en la literatura infantil y juvenil: Personajes analfabetas y "abyectos"
}

\author{
Evelyn Arizpe \\ Universidad de Glasgow, Escocia \\ Artículo recibido 13/04/2015, aceptado 5/5/2015, versión final 21/09/2015 \\ DOI: http://dx.doi.org/10.5565/rev/jt13.655
}

\section{Resumen}

La presencia de los libros, los lectores y la lectura en la literatura infantil y juvenil es más común de lo que pensamos y sin embargo, siguen siendo una minoría los libros donde aparece el acto de la lectura como algo más que una herramienta para obtener información. La presencia o ausencia de las representaciones son indicadores de la forma en que la sociedad construye la relación entre los niños y jóvenes y la lectura. Este artículo analiza un grupo de textos donde aparece el tema de la alfabetización en cuanto a personajes que pueden considerarse como "abyectos" según el trabajo de Julia Kristeva (1982), en este caso, niños y jóvenes que viven en los márgenes de la sociedad, en la calle o en el tiradero. Las consecuencias de aprender a leer no siempre son las que nos imaginamos ya que tienen el poder de subvertir a las autoridades opresivas. El artículo se refiere también al Proyecto "Reading Fictions" dentro del cual se llevó a cabo este estudio.

Palabras clave: lectura en la literatura infantil y juvenil, alfabetización, abyección, niños marginalizados

\begin{abstract}
The presence of books, readers and reading in children's and young adult literature is more common than we think and yet books where the act of reading appears as something more than a tool to obtain information are in a minority. The presence or absence of these representations are indicators of the way in which society contructs the relationship between children and young people and reading. This article analysis a group of texts where the theme of becoming literate is linked to characters who can be described as "abject" according to the work of Julia Kristeva (1982), in this case, children and young people who live on the margins of society, in the street or in the rubbish dump. The consequences of learning to read are not always those we imagine given they have the power to subvert oppressive authority. This article also refers to the Project "Reading Fictions" within which this study took place.
\end{abstract}

Keywords: reading in children's literature, becoming literate, abjection, marginalized children

\section{Résumé}

La présence des livres, des lecteurs et de la lecture dans la littérature pour les enfants et les jeunes est plus courante que nous croyons, 
néanmoins, les livres dans lesquels l'acte de la lecture apparaît comme plus qu'un moyen d'obtenir d'information, sont dans la minorité. La présence ou l'absence des représentations sont indicatives de la manière dans laquelle la société construit la relation entre les enfants, les jeunes et la lecture. Cet article analyse un groupe de textes dont le thème de l'alphabétisme est lié aux caractères qui peuvent être décrits comme "abject" selon les idées de Julia Kristeva (1982), ces enfants et ces jeunes qui habitent les bords de la société, la rue ou la décharge. Les conséquences d'apprendre à lire ne sont pas celles que nous pouvons prévoir parce qu'elles ont le pouvoir de subvertir l'autorité oppressive. Cet article se réfère aussi au Projet "Reading Fictions" dans lequel ces recherches avaient lieu.

Mots clefs: la lecture dans la littérature pour les enfants et les jeunes, l'alphabétisme, abjection, des enfants marginalisés

\section{Introducción: la representación de la lectura}

A pesar de los presagios sobre la desaparición del libro o quizá debido a ello, parece que el libro como objeto no cesa de fascinarnos. Y a pesar de los cambios en las prácticas lectoras y de los descubrimientos de la neurociencia en cuanto a lo que sucede en nuestros cerebros cuando leemos, el acto de la lectura continua siendo un misterio. Quizá es por ello que las representaciones de los libros, los lectores y la lectura aparecen a lo largo de la historia, y continúan apareciendo, en el arte, la fotografía y en la literatura misma. Existen cientos de textos literarios que giran en torno a un libro o un manuscrito o en los cuales se retratan lectores y actos de lectura. Parece que cada año aparecen más novelas para adultos - algunos "best-sellers" - sobre el tema de la lectura o los libros: libros fantásticos, lecturas peligrosas, libros con claves o lecturas prohibidas que pueden llevar a los personajes a la búsqueda, la persecución, la locura o incluso el asesinato y la muerte. Pensemos en las metaficciones de Jorge Luis Borges o Italo Calvino, pero también en los libros de Umberto Eco, Roberto Bolaño, Arturo Pérez-Reverte y Carlos Ruíz Zafón, entre otros.

Propongo que una manera de entender mejor esta fascinación y también los cambios que están sucediendo en torno al libro y la lectura es analizar las representaciones de lectores y actos de lectura en los libros para niños y jóvenes. Su presencia puede iluminar la forma en que se concebía esta actividad en la construcción de la infancia en el pasado y dar pautas para comprender las transformaciones actuales que surgen a partir de las nuevas tecnologías. También, y quizá más importante, este análisis puede ofrecernos una indicio sobre el futuro de los libros y la lectura, ya que estas representaciones son formativas para las ideas de los niños y jóvenes lectores contemporáneos en cuanto a lo que significa ser lector. Por otro lado, 
la ausencia de estas imágenes en la literatura infantil o juvenil puede ser igualmente significativa y vale la pena considerar, por ejemplo, la total omisión de la lectura por placer en la serie Harry Potter.

En su reciente libro sobre metáforas sobre lectores y lectura, Alberto Manguel (2013) escribe que al lector empedernido, al ratón de biblioteca (o "bookworm" en inglés), se le considera tanto sabio como idiota, alguien que devora libros y termina por confundir la realidad y la ficción. Obviamente Don Quijote es el ejemplo por quintaesencia. A estos seres se les acusa de vivir en un mundo imaginario que no tienen ninguna utilidad práctica. Manguel sostiene que esto se debe a la sensación de malestar que el arte de la lectura ha causado desde los días de la scriptoria mesopotámica y egipcia, un arte sospechoso por ser a la vez prodigioso y peligroso. Dice que las sociedades siempre han desconfiado de lo que puede crearse a través de las palabras. "La Palabra" crea universos enteros. Este recelo al poder mágico de las palabras, sugiere Manguel, se encuentra detrás de la mayoría de las censuras, quemas de libros y burlas al arte lector (Manguel, 2013).

Esta actitud se manifiesta con una inquietud particular ante el sexo femenino y la juventud. Recordemos lo que le sucedió a Emma Bovary o a la prima de la Quijotita, con sus desmedidas nociones sobre el amor derivadas de novelas románticas. Manguel nos recuerda también la primera escena del El rojo y el negro de Stendhal donde el padre de Julián le arrebata el libro que el muchacho lee en vez de tender al molino. Podemos recordar también la primera escena de Jane Eyre de Charlotte Brontë donde, tras quitarle a Jane el libro que la niña lee escondida tras una cortina, su joven primo se lo avienta con intención de pegarle. La lectura por placer distrae del trabajo y las obligaciones y puede comunicar ideas subversivas o inmorales, "dañando" a aquellos "inocentes" quienes se considera que no poseen un juicio lo suficientemente maduro, racional o crítico para rebatir estas malas influencias.

\section{Libros, lectores y lectura en la literatura infantil y juvenil}

En la literatura infantil y juvenil, las representaciones de libros, lectores y lectura se encuentran tanto en libros álbum como en cuentos y novelas: además de la icónica Matilda, quien lee a pesar de la incomprensión y amenazas de sus padres, tenemos actos de lectura y lectores memorables, por ejemplo, en La historia interminable de Michel Ende, El increíble niño comelibros de Oliver Jeffers, El mago de Tierramar de Ursula Le Guin, Corazón de tinta de Cornelia Funke, La ladrona de libros por Markus Suzak y Bajo la misma estrella de John 
Green, por citar solamente algunos de los más conocidos internacionalmente. En estos libros, la lectura se presenta como un escape o consuelo, como una forma de obtener conocimientos o poder, como una forma de compartir el amor o buscar el significado de la vida. Aun cuando resulta que la lectura desata eventos inesperados y a veces amenazantes o peligrosos, al final de cuentas, como resultado de sus actos lectores, la mayoría de los personajes crece interiormente o resulta más sabia en su interacción con la realidad.

Por lo tanto, algunas de las preguntas que surgen al considerar este tema son las siguientes: ¿Cómo se presenta al lector, al libro y al acto de la lectura en la literatura infantil y juvenil? ¿Cómo son y qué significan esas representaciones en nuestros días? ¿Cómo fueron en el pasado? ¿Cómo han cambiado? ¿Qué sucede cuando están ausentes? ¿Qué nos dicen sobre lo que estamos experimentando ahora, en la era digital? Para comenzar a responder a estas preguntas, invité a una amiga y colega, Vivienne Smith, a realizar una investigación conjunta pero pronto nos dimos cuenta que el tema nos rebasaba y era imposible abarcar todas las obras con referencias a este tema. Decidimos organizar una serie de cinco talleres intensivos e invitamos a algunos de los más destacados críticos del mundo de la literatura infantil y juvenil en lengua inglesa, además de especialistas en lectura, sociólogos y profesionistas en medios para niños. Los participantes fuimos Kim Reynolds, Morag Styles, Maria Nikolajeva, Mary Anne Wolpert, Sylvia Warnecke, Jean Webb, Prue Goodwin, Peter Hunt, Maureen Farrell, Julia Eccleshare, Shirley Brice Heath, Vivienne Smith y yo. Algunas de las ideas que surgieron en estos talleres pueden leerse en el blog: Reading Fictions (http://readingfictions.blogspot.mx/p/about-project.html). Este artículo tiene como base mi presentación en los talleres pero termina con algunas de las conclusiones individuales y colectivas del proyecto. ${ }^{\mathrm{i}}$

Mi contribución analiza un grupo de libros donde uno de los temas fundamentales es el analfabetismo y lo que esto significa para los personajes. Aprender o no a leer es central a la trama y siempre acarrea consecuencias, aunque resulta que nos siempre es la panacea que los lectores, dentro y fuera de libro, esperan. Por otro lado, en muchos casos también resulta que el deseo de aprender a leer y/o el amor por los libros indican que los personajes tienen ciertas cualidades morales a pesar de ser repudiados por la sociedad.

En seguida haré un brevísimo resumen de estos libros ya que no todos están traducidos o son conocidos fuera de contextos anglosajones. 
Smith por Leon Garfield (1968). Trata de un niño ladrón quien al robar una cartera roba sin querer también un documento. Intuye que es importante, ya que asesinan al portador poco después del robo, pero como no sabe leer y no confía en nadie, intenta aprender a leer.

Lee Raven Boy Thief (Lee Raven joven ladrón) por Zizou Corder (2008). Otro joven ratero roba un libro por accidente. El libro resulta ser mágico por lo cual es perseguido por varias personas poderosas.

Holes (Hoyos) por Louis Sachar (2000). Los jóvenes internados como castigo penal en un campamento, supuestamente de rehabilitación, son forzados a cavar hoyos. Stanley y su amigo Zero logran escapar y encontrar el tesoro que las autoridades del campamento estaban buscando.

Trash (Reyes de la basura) por Andy Mulligan (2010) trata de unos chicos pepenadores que encuentran una cartera llena de dinero y la ocultan, pero son perseguidos también por las autoridades y personajes corruptos.

En The Baby and Fly Pie (El bebé y Fly Pie) por Melvin Burgess (1993), un niño y su hermana viven en un basurero donde trabajan como pepenadores. Se encuentran un bebé secuestrado y deciden cuidarlo y pedir la recompensa, pero las cosas no resultan tan sencillas.

A pesar de que hay muchas diferencias entre los textos, fueron las semejanzas las que me llamaron la atención, comenzando por el hecho de que la pobreza es casi siempre la causa principal de la ignorancia y analfabetismo. Los personajes viven en situaciones sociales y económicas precarias y tienen que ganarse la vida de algún modo lo cual conduce a algunos de ellos al robo o al trabajo en los tiraderos de basura. Casi todos son niños abandonados o distanciados de sus padres, víctimas del abuso de los adultos, por lo cual viven en la calle o los mismos tiraderos. Dado que son rateros y depredadores, son considerados amenazas al orden establecido. Por casualidad, los personajes encuentran o se roban algo que no les pertenece, una cartera, un maletín, un bebé o un libro mágico. Es significativo que, en el caso de Smith y Lee Raven, son textos que no pueden leer. Los jóvenes no quiere devolver lo que encontraron hasta poder "descifrarlo" de alguna manera ya con ello creen ver una pequeña luz de esperanza para sus futuros. Esta decisión es el disparador para el resto de la historia y resulta evidente que no sólo es necesario saber leer palabras escritas sino también saber "leer" situaciones y personas, ya que, como consecuencia, sufren una variedad de peligros: persecución, encarcelamiento e inclusive tortura.

Otra semejanza es que estos niños con frecuencia son descritos con cualidades roedoras. Son ágiles y vivos, conocen bien las calles y se pueden mover de forma casi 
invisible por los callejones y las cloacas. Curiosamente, en la literatura infantil, la mayoría de los animales retratados como lectores son ratas o ratones y hay un paralelismo notable entre los libros sobre roedores alfabetizados y estos libros sobre niños de la calle. No sólo es que se considera que estos seres deben ser analfabetas, sino que también deben ser iletrados, es decir que se supone que su ignorancia va de la mano con una falta de interés o de habilidad para apreciar la lectura. Sin embargo, a final de cuentas, resulta que algunos, sobre todo los roedores, son más letrados y aprecian más la literatura y los libros que la mayoría de los humanos.

\section{El analfabeto como personaje abyecto}

No hay espacio en este artículo para tratar el tema de los roedores, ${ }^{\text {ii }}$ sin embargo, vale la pena resaltar que tanto éstos como los niños de la calle de alguna manera transgreden el orden natural establecido y ocupan una zona fronteriza, un espacio híbrido entre el mundo animal y el humano. Sean roedores o jóvenes, estos personajes están al borde de los márgenes de la sociedad y son vistos como sabandijas o parásitos, despreciados y odiados por la estabilidad social y política. Christine Wilkie-Stibbs (2008) se basa en las ideas sobre lo abyecto de Julia Kristeva (1982) para ayudar en su análisis sobre el niño que queda "afuera” y a su vez, sus ideas pueden aplicarse tanto a los niños de la calle como a los roedores: 'Their bodies are excluded, rejected, extinguished, mistreated, or hidden; they are all conjectured in alterity and identified in the narratives as being in some way different...' (Wilkie-Stibbs, 2008, p. 81). ("Sus cuerpos son excluidos, rechazados y extinguidos, maltratados o escondidos, todos son conjeturados en la alteridad e identificados como diferentes en la narrativa." $)^{\mathrm{iii}}$

En este grupo de libros, los personajes humanos viven excluidos y escondidos entre los deshechos, la mugre y el cochambre, en tierras de nadie, en cloacas y basureros. Por ende, los cuerpos de los seres que viven en estos sitios son diferentes, "otros", y resultan repulsivos por su suciedad y sus secreciones. En estos lugares, la racionalidad y los significados se fracturan y trastornan, dando lugar a otras jerarquías y formas de vivir. Los roles se invierten: a estos niños (y roedores) nadie los cuida y tienen que ser más listos que los adultos abusivos que los rodean para sobrevivir y quizá, poder escapar de estos lugares infernales.

Una de estas estrategias de sobrevivencia es alfabetizarse, sin embargo, dado que la alfabetización permite el acceso a la información y puede llevar a la concientización, la crítica y el deseo de transformación (Freire, 1972), resulta ser una amenaza para el orden establecido ya que tiene la capacidad de subvertirlo. 
Casi todos los libros mencionados en esta comunicación son para buenos lectores, preadolescentes o adolescentes; en otras palabras, son para lectores que son (o deberían ser) alfabetos. Por lo tanto, la intención de los autores de los libros sobre niños analfabetos no es promover al alfabetismo (como es el caso de algunos libros álbum o cuentos para niños a punto de aprender a leer) sino crear una situación donde un lector pueda imaginar lo que es el no poder leer.

\section{El silencio y el lenguaje}

Loss of language is the symptom of the abject status of all of these child figures who share in the same semiotic space of effacement through their mutual experiences of being hidden or defaced bodies, of becoming 'strays', by being rootless and displaced, by their mutual experience of incarceration or immobilization, and by their impotence and curtailed freedom in the face of some form of oppressive power. (Wilkie-Stibbs, 2008, p. 91)

(La pérdida del lenguaje es el sintoma del estatus abyecto de todas estas figuras de niños que comparten el mismo espacio semiótico de anulación a través de sus experiencias mutuas de ser cuerpos escondidos o desfigurados, de volverse extraviados, por no tener raíces y ser desplazados, por su experiencia mutua de encarcelamiento o inmovilización y por su impotencia y libertad frente a algún tipo de poder opresivo.)

Wilkie-Stibbs se refiere también a las ideas de Judith Butler sobre poder y lenguaje para examinar al "outside child" o niño en los márgenes en la literatura infantil y para ayudar a iluminar algunas características de los sujetos analfabetos, en especial a los niños que han sido expulsados a la calle o al basurero. Para Butler, "la subordinación del sujeto sucede a través del lenguaje" (cita in Wilkie-Stibbs, 2008, p. 90). Wilkie-Stibbs aplica esta idea a la falta de lenguaje en los personajes la cual los marca como impotentes, silenciados y por lo tanto víctimas “ para ser explotados, borrados y exterminados” (Wilkie-Stibbs, 2008, p. 91). De acuerdo a Freire (1972), la falta de acceso a la palabra escrita también es una forma de opresión dado que las autoridades controlan tanto el acceso a los textos como al aprendizaje. Es común encontrar en la literatura para jóvenes, sobre todo en fantasías y distopías, descripciones de gobiernos autoritarios que ejercen el poder a través de la destrucción o censura de libros y de un rígido aparato educativo que distingue entre los que pueden o no pueden leer.

La voz de un personaje va estrechamente ligada a al nombre propio y la habilidad de escribir ese nombre puede considerarse como el primer acto de un sujeto que se asume como 
tal. Esto ocurre en varios de los libros aquí mencionados. En el libro de Garfield, para empezar, Smith no parece tener un nombre de pila, sólo se le conoce como 'Smith' o 'Smut' (en inglés, “Tizón”, otra referencia a la mugre que parece parte de su ser). En el libro de Corder, Lee Raven utiliza un nombre falso, 'Joe English', un nombre genérico, para evadir a la policía. A uno de los protagonistas en Reyes de la basura, se le conoce simplemente como "Rata", pero al final del libro abandona su apodo y retoma el nombre de Jun-Jun. A “Zero", uno de los personajes que resulta centrales en Hoyos, se le niega un nombre propio hasta que puede leer y escribir. Hacia el final del libro, "Zero" revela su verdadero nombre.

Se entiende entonces que la falta de acceso al lenguaje escrito es también una metáfora para la exclusión del hogar y de la sociedad en general; una exclusión que lleva a la explotación, por ejemplo de parte de los adultos que controlan los tiraderos. Por su parte, Lee huye de su casa por culpa de su padre, un criminal violento quien lo agrede, como también agrede a su madre y sus hermanos. De entre estos niños de la calle, Smith es quien tiene más agencia. Es independiente pero tiene un hogar, aunque es pobre y caótico, y sus hermanos lo quieren a su manera. Es cierto que tanto Smith como algunos de los otros personajes logran hacer amistad con algunos adultos amables, pero por lo general, los adultos los consideran un estorbo y hasta los llaman "basura". En algunos casos hasta intentan desaparecerlos, como cuando "Zero" es descrito como un "nadie" por Mr Pendanski y la Directora da la orden de destruir todos sus registros pensando que nadie se iba a dar cuenta. La violencia contra los niños marginados hasta el grado de eliminarlos aparece de manera aún más realista y perturbadora tanto en el libro de Mulligan como en el de Burgess.

\section{Lo sucio y lo pulcro}

Como ya he mencionado, la relación entre los cuerpos de los niños y lo "pulcro" o "sucio" es un tema constante en estos libros. Aunque Kristeva no se refiere a la relación entre la suciedad y la abyección, esta relación ocurre en la descripción de las inmundicias y los fluidos malolientes que parecen acompañar a los jóvenes, como si fueran parte intrínseca de sus cuerpos. Los espacios que son forzados a habitar, fuera del sistema, contribuyen a esto, ya que son infra-mundos creados por los desechos, por lo que ese mismo sistema prefiere ocultar en la basura o el drenaje. Dada su apariencia, que se percibe como un indicador de enfermedad y de maldad, la gente ignora o evita a los muchachos. Lee Raven es descrito como "horriblemente mugroso" y se vuelve aún más asqueroso tras escapar de sus perseguidores por las cloacas Londinenses, donde chapotea en el excremento, la grasa y el fango (y resulta 
que efectivamente contrae una enfermedad por orina de rata). En cuanto a Smith, se sugiere que la mugre y la suciedad son partes esenciales de su ser y el narrador nos dice que hasta la Muerte lo ha evitado por miedo a contagiarse de algo.

Resulta simbólico que Smith se baña por primera vez cuando está a punto de aprender a leer. Son necesarias tres horas para que quede limpio y parece perder algo de sí mismo en el proceso. Ropa limpia y cuerpo aseado se asocian con la urbanidad y la educación y por lo tanto con aprender a leer. Sin embargo, como exclama el carcelero, la mugre de Smith escondía una "multitud de pecados" y ahora su aseo ha llevado a que salgan a la luz. Su pulcritud resulta entonces superficial, como también lo es el aprendizaje. Los "pecados" llegan muy hondo, tanto así que cuando echan a Smith a la famosa prisión de Newgate, acusado (falsamente) de asesinato, sus ropas nuevas y finas se desgarran y el niño rápidamente se cubre de nuevo de inmundicias porque tiene que dormir sobre cenizas. A pesar de ser inocente, es sólo tras una larga caminata por la nieve pesada y blanca y un encuentro cercano con la muerte que Smith puede "limpiarse" de nuevo y logra salir de la pobreza.

\section{Aprender o no a leer}

No todos los niños de la calle y del basurero aprenden a leer en el transcurso de sus historias. Los que sí aprenden, tienen primero que encontrar alguien que quiera enseñarles y esto no resulta tan fácil. Smith le pide a un deudor encarcelado, a un abogado, a un administrador, a un maestro de escuela, a un librero y a un sacerdote. No sólo le aconsejan que no se moleste en aprender porque piensan que no le aportará ningún beneficio, sino que algunos le pegan por andar molestando. La ironía es que, como el mismo Smith observa, la única persona que es amable con él es un magistrado pero no puede enseñarle porque es ciego.

Rafael, el personaje de Reyes de la basura vive en el tiradero y es un pepenador, pero no sólo ha aprendido a leer en la escuela de la misión sino también ha aprendido a usar una computadora. Es un chico listo que intuye los problemas que puede traerle el no devolver la cartera, pero también sabe que es su única oportunidad de escapar de esa vida. Cuando es interrogado y torturado por la policía, éstos se enteran que sabe leer y exclaman, 'This piece of shit can read? ... Who taught trash to read?’ (Mulligan, 2010, p. 262) (‘Este pedazo de mierda puede leer? ¿Quién le enseño a leer a esta basura?'). El valor de la lectura les es negado a estos "no-sujetos" por las autoridades que ven en esta actividad una amenaza potencial al poder opresivo del sistema. Nos recuerda que el acto de aprender a leer es un asunto que va más allá del deseo y la oportunidad de una persona, y de la funcionalidad de 
este acto, como dice James Gee: 'Literacy as "the ability to read and write" situates literacy in the individual person, rather than in society. As such it obscures the multiple ways in which literacy interrelates with the workings of power' (Gee, 1996, p. 22) (La alfabetización como 'la habilidad de leer y escribir sitúa al alfabetismo en el individuo y no en la sociedad. Como tal, oscurece las múltiples maneras en que la alfabetización se interrelaciona con los funcionamiento del poder'.)

Junto con la falta de oportunidad, hay otras razones por las cuales los otros personajes son analfabetos, pero ninguno tiene que ver con falta de inteligencia. Zero es brillante en cuanto a las matemáticas y rápidamente aprende a leer cuando alguien tiene la paciencia de enseñarle. Lee Raven ha sido diagnosticado como disléxico, dice que las letras "bailan" y no las puede descifrar, así es que no significan nada para él. Pero para su intolerante padre, esto significa ser "ESTUPIDO". Sabe que los libros son importantes y quisiera leerlos pero no le gustan porque no tiene acceso a lo que contienen. Por otro lado, posee destrezas útiles tales como robar carteras, abrir cerraduras y tener de memoria un mapa de los túneles y cloacas de Londres. Además nos dice, con orgullo, "I can learn anything, anywhere, any time. I learned a lot off the telly - history channels and that - and I keep my ears open." (Corder, 2008, p. 63) (Puedo aprender cualquier cosa, en cualquier lado, en cualquier momento. Aprendí mucho de la tele, canales de historia y eso, y tengo aguzados los oídos).

El libro que Lee se roba es un libro mágico que tiene la capacidad de convertirse en cualquier texto que el lector quiere que sea (algo así como el libro que aparece en el cuento de E.T.A. Hoffman, "La elección de la novia", una especie de Kindle empático). Sin embargo, dado que Lee no puede leer, el libro se ve forzado a usar su voz para contarle cuentos, y los primeros cuentos que le cuenta son de su comic favorito, el único libro que recuerda que su madre le leía antes de que su padre lo echara al fuego. El adolescente y el libro mágico desarrollan una relación especial y se vuelven amigos, tanto así que una enorme recompensa no tienta a Lee a regresar el libro. Sabe que el libro es algo especial y siente que debe cuidarlo y protegerlo. Cuando la villana Nigella le roba el libro y crea una máquina que exprime al libro de todas sus historias (ella es una autora frustrada porque no tiene ideas), Lee lo rescata. El libro está casi "muerto", sin nada que contar pero Lee lo cuida, pegado a su pecho. Cuando el libro se recupera, en un giro metaficcional, se convierte en el libro que el lector real tiene en sus manos, Lee Raven, Boy Thief. 


\section{Las consecuencias de alfabetizarse}

La sociedad frustra los intentos de los personajes para alfabetizarse por miedo a la perturbación del 'status quo' al crear “concientización” que puede llevar a la acción por transformación social, por la justicia y la democracia. Es justamente lo que dice el ensayista, Juan Villoro (al escribir sobre la masacre de los estudiantes de la escuela normal en Ayotzinapa, en México) basándose en El último lector de Ricardo Piglia:

Hay una tensión entre leer y la acción política”, escribe Ricardo Piglia. Interpretar el mundo puede llevar al deseo de transformarlo. En ocasiones, la letra, y la ortografía misma, son un gesto político que desafía un orden bárbaro: "Podríamos hablar de una lectura en situación de peligro. Son siempre situaciones de lectura extrema, fuera de lugar, en circunstancias de extravío, o donde acosa la amenaza de una destrucción. La lectura se opone a una vida hostil. (Villoro, 2014)

En estos libros, las consecuencias de aprender a leer o por lo menos de hacer el intento, no siempre son las que esperamos, sin embargo, aun cuando las consecuencias no siempre acarrean los beneficios tradicionales, en todos los casos, lo que es crucial es aprender a apreciar lo que significa leer. Para los niños de la calle o del tiradero, las consecuencias tienen que ver con aventajar a los adultos abusivos y/o vengarse de a las autoridades que permiten estos abusos. La nueva habilidad de Zero para leer el nombre de Stanley Yelnats en la maleta enterrada conduce al descubrimiento de la verdad sobre Camp Greenlake y al encarcelamiento de los adultos involucrados. En Los reyes de la basura, Rafael y Jun-jun logran escapar del basurero y de las autoridades sádicas además re-distribuir el dinero robado por el oficial corrupto entre los más necesitados. La lealtad de Lee Raven hacia su amigo el libro mágico lo lleva a él y a sus hermanos a por fin poder confrontar a su violento padre (Lee no aprende a leer pero queda claro que es peor ser poco creativo que analfabeta, como lo ilustra la villana Nigella). Parece que los autores de estos libros nos sugieren que a pesar de que estos niños son materialmente pobres, tienen muchas riquezas intangibles que ofrecer, tales como empatía, amistad y lealtad.

El encuentro de Smith con el magistrado, quien normalmente hubiera sido su víctima, cambia la vida del joven, pero el autor nos indica en varias ocasiones que en Smith existe una bondad desde el principio, un sentimiento humano que lo lleva a ayudar al ciego en vez de robarle. Cuando su victoria en su "batalla" por leer es confirmada por su maestra, la hija del magistrado que al principio lo trata con sospechas, el corazón de Smith "brinco casi hasta los cielos" lo cual sugiere tanto virtud como el estatus de clase elevada a la cual aspira y eventualmente obtiene. Entonces, una de las consecuencias que conlleva el acto de lectura, y que es similar en todos estos libros aquí mencionados es que debajo de las capas de 
ignorancia, delincuencia, mugre, basura o enfermedad, estos sujetos son moralmente "buenos" no obstante sus "crímenes" anteriores. El alfabetismo y la lectura son relacionadas a la pulcritud, no necesariamente del cuerpo pero sí del alma, y por lo tanto a la moral. Más aún, como consecuencia, tanto su creatividad y su bondad se ven incrementadas y por lo tanto pueden causar transformaciones en la misma sociedad al principio los rechazó.

Sólo uno de los libros aquí analizados se desvía de forma significativa de este tipo de final: The Baby and Fly Pie. En primer lugar, no es el niño llamado 'Fly Pie' sino su hermana Jane quien intenta aprender a leer para escapar de la pobreza y la esclavitud como pepenadores. Es significativo que ella sí tiene nombre mientras que a él sólo se le conoce por su apodo. Así nos presenta Fly Pie a su hermana:

She was a good girl, you know the sort. While the rest of us were out having a good time, Jane would stay in and wash her clothes or do her hair. She was always trying to learn things - reading and writing or sewing or adding up. She was stupid. Who needs to read and write on a rubbish tip? But she did it anyway and [...] she always turns out in a clean dress with her hair brushed and her good manners, even when she's had to walk through the dirt to get there. (Burgess, 1993, p. 31)

Era buena niña, ya conocen ese tipo. Mientras que los demás estábamos fuera pasándola bien, Jane se quedaba adentro y lavaba su ropa o se peinaba. Siempre estaba tratando de aprender cosas, leer y escribir o coser o sumar. Era estúpida. ¿Quién necesita leer y escribir en un basurero? Pero lo hacía de todas maneras ... siempre sale con un vestido limpio y peinada y con buenos modales, aun cuando ha tenido que caminar entre la mugre para llegar.

Al final, ninguno de los intentos de Jane por estar limpia o ser "buena" o aprender a leer le es de utilidad. Las circunstancias la obligan a ser prostituta y en las últimas páginas del libro, la ejecutan con un disparo. Ni subvierte al sistema, ni se escapa y su hermano, analfabeto, vuelve a los tiraderos. Es interesante también considerar que Jane es el único personaje femenino entre estos libros, en la escala de jerarquías, el ser mujer la sitúa en el escalón más bajo y no obstante su empeño, el sistema la reprime y la desaparece.

\section{Conclusiones e inquietudes}

En los talleres del Proyecto "Reading Fictions" no pudimos abarcar todas las obras ni discutir todos los temas que hubiéramos querido, por ejemplo, el papel de las bibliotecas; la representación de la escritura o personajes escritores y la representación de la lectura en pantalla. Además, nos quedamos con más preguntas e inquietudes que conclusiones, ya que, a pesar de que encontramos una gran cantidad de representaciones de lectores y lectura, su ausencia es más común. Esto puede deberse al hecho que representar a un personaje que lee 
por placer es bastante aburrido, es una actividad que se lleva acabo a solas, en silencio y "no pasa nada". Ni siquiera en las trama ubicadas en la escuela se presenta la lectura como placentera, si acaso, se presenta como aburrida y forzada. Pensemos, como ya dije, en la serie de Harry Potter donde la única persona que lee es la estudiosa Hermione y nunca se le ve leyendo por placer sino siempre para alguna tarea escolar o para resolver un misterio. ¿Qué mensaje sobre la lectura comunica esta serie a millones de lectores?

Cuando aparecen las representaciones tienden a ser sobre todo negativas: los lectores suelen ser "distintos", solitarios, excluidos (y con lentes), muy opuestos a los atractivos, populares "no-lectores". Gracias a sus conocimientos o experiencia a partir de sus lecturas, estos personajes logran sus objetivos pero al mismo tiempo, casi siempre pierden su inclinación por leer. La pregunta es entonces: si insistimos que la lectura es importante y valiosa, ¿por qué se presentan tan negativamente a los lectores y a la lectura? ¿Por qué decide un autor incluir a un personaje lector o a un libro que requiere ser leído?

En cuanto al libro como objeto y el debate sobre su desaparición, parece que también comienzan a aparecer estas inquietudes en los mismos libros. Por ejemplo, en Lee Raven Boy Thief, se invita al lector a considerar al "objeto libro". El libro mismo es consciente de su propia naturaleza y del cambio que experimentó cuando pasó de ser papiro a vitela y luego a un libro de papel. Se preocupa sobre su siguiente cambio en el mundo digital:

Could I now become bytes or bits? A disc or a pod, like the boy said - a pod full of binary code? This has been beginning to happen to stories. They are taking another new form... I had changed before and I will change again no doubt. Even so, I shivered a little at the thought. Am I ready to become a piece of technology? (Corder, 2008, p. 125)

¿Podría convertirme en bytes o bits? Un disco o un pod como dijo el chico, ¿un pod lleno de código binario? Esto es lo que comienza a sucederle a los cuentos. Están tomando otra nueva forma ... yo he cambiado antes y seguramente cambiaré de nuevo. Sin embargo, temblé un poco al pensarlo. ¿Estoy listo para convertirme en un pedazo de tecnología?

Rompiendo con el esquema que he creado con el análisis de este corpus pero siguiendo con el tema de los niños marginados, quiero terminar este texto con la imagen final de un libro álbum: Los niños del mar, de Jaume Escala y Carmen Solé Vendrell. En esta obra, basada en el poema de Escala, vemos como un señor se encuentra con un niño en la playa y le cuenta cuentos fantásticos. El niño lo escucha pero sus respuestas y las ilustraciones nos muestran que él interpreta los cuentos de diferente forma, según la realidad que conoce, la de los niños que viven en la pobreza y el abandono. Al final de la obra el señor le obsequia el 
libro de cuentos, aparentemente sin darse cuenta de que lo que el niño tiene es frío. La última imagen nos muestra que ha utilizado el libro para alimentar la fogata y calentarse. En los mundos distópicos y en algunas realidades, los libros y las historias que contienen ni se convierten en tecnología ni tienen futuro. Esta imagen final, escalofriante, nos deja sorprendidos y sacudidos, sobre todo a quienes amamos a los libros y creemos (o quisiéramos creer) que tienen el potencial para cambiar al mundo.

Una cita de Nikolajeva tomada de su trabajo para el proyecto "Reading Fictions", resume todo lo dicho:

The educational project of children's literature makes the appearance of books, readers and reading an ethical statement. If we accept the claim that access to literacy and reading is a matter of social justice, then certainly fictional readers can potentially provide excellent role models for real young readers. ${ }^{\text {iv }}$

El proyecto didáctico de la literatura infantil implica que la apariencia de libros, lectores y lectura sea una declaración ética. Si aceptamos que el derecho al acceso a la alfabetización y a la lectura es una cuestión de justicia social, entonces por supuesto que los lectores ficticios pueden, potencialmente, ofrecer modelos excelentes para jóvenes lectores reales.

En otras palabras: la presencia o ausencia de los libros y las consecuencias de aprender a leer en la literatura infantil y juvenil son tan significativas como lo pueden ser en las vidas reales de los niños y los jóvenes.

\section{Referencias bibliográficas}

Burgess, M. (1993). The baby and fly pie. London: Puffin Books.

Corder, Z. (2008). Lee raven boy thief. London: Puffin Books.

Freire, P. (1972). Pedagogy of the oppressed. Harmondsworth: Penguin

Garfield, L. (1968). Smith. Harmondsworth, Middlesex: Puffin Books.

Gee, J. P. (1996). Social linguistics and literacies: Ideology in discourses. London: Routledge Falmer.

Kristeva, J. (1982). Powers of horror. An Essay on abjection (trans. L. S. Roudiez). New York: Columbia University Press.

Manguel, A. (2013).The traveler, the tower, and the worm. Reading as metaphor. Philadelphia: University of Pennsylvania Press.

Mulligan, A. (2010). Trash. London: David Fickling Books.

Sachar, L. (2000). Holes. London: Bloomsbury.

Villoro, J. (2014). "Yo sé leer: vida y muerte en Guerrero. El País. Online. 24 de octubre. Retrieved from http://elpais.com/elpais/2014/10/24/opinion/1414176761_858161.html

Wilkie-Stibbs, C. (2008). The outside child in and out of the book. London: Routledge.

\footnotetext{
${ }^{i}$ E1 Proyecto "Reading Fictions" recibió una beca de The British Academy. El libro de ensayos, Children as readers in children's literature: The power of texts and the importance of reading, editado por Arizpe y Smith, se publicará en 2015 (Routledge).
} 


\footnotetext{
ii Ver mi ensayo, "Of Readers and Vermin: The consequences of literacy for 'parasites"” en Arizpe y Smith 2015.

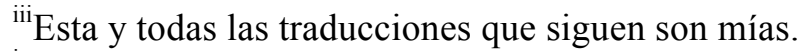

${ }^{\text {iv }}$ El ensayo de Nikolajeva “"Everybody knew that books were dangerous': Cognitive and affective responses to representation of books and reading" se publicará en Arizpe y Smith 2015.
}

\section{Información de la autora:}

Evelyn Arizpe es Profesora en la Facultad de Educación, Universidad de Glasgow, donde coordina el máster en educación "Children's Literature and Literacies". Ha impartido cursos y publicado en las áreas de literatura infantil y juvenil y prácticas lectoras y presentado ponencias en congresos internacionales. La Dra. Arizpe ha llevado a cabo varios estudios relacionados con libros álbum y respuestas lectora, tanto con niños como con adolecentes. El más reciente fue el proyecto de investigación internacional, Visual Journeys through Wordless Narratives sobre la respuesta lectora de niños inmigrantes al álbum sin palabras de Shaun Tan, Emigrantes (Arizpe, E., Colomer, T. y Martínez-Roldán, C., con Bagelman, C., Bellorín, B., Farrell, M., Fittipaldi, M., Grilli, G., Manresa, M., Margallo, A.M., McAdam, J., Real, N. and Terrusi, M., 2014, Bloomsbury Academic) Actualmente, con Morag Styles, prepara una nueva edición de Lectura de imágenes (Fondo de Cultura Económica).

Email: Evelyn.Arizpe@glasgow.ac.uk

To cite this article:

Arizpe, E. (2015). Libros, lectores y lectura en la literatura infantil y juvenil: Personajes analfabetas y "abyectos". Bellaterra Journal of Teaching \& Learning Language \& Literature, 8(4), 9-23. DOI: http://dx.doi.org/10.5565/rev/jt13.655 